\section{SHEA Election/ Membership Notice}

If you have not yet received the SHEA elections ballet and/or the SHEA membership directory, your membership may be in arrears. If you have questions, please contact our executive office at 875 Kings Highway, Suite 200, West Deptford, NJ 08096. Telephone (609) 8451636. FAX (609) 853-0411.

\section{SHEA \\ Membershi List Available}

A SHEA membership list is available for individuals or organizations who want to target mailings to hospital epidemiologists and other infectious disease specialists. The costs for a one-time mailing list are as follows: a commercial business, $\$ 500$; a not-for-profit organization, $\$ 150$; and a member using the list for research purposes, $\$ 50$. To order the list, contact SHEA, 875 Kings Highway, Suite 200, West Deptford, NJ 08096. Telephone (609) 845-1636.

Bri ef items of interest for the SHEA New sletter may be sent to Robert A. Weinstein, MD, SHEA Newsletter Editor, Division of Infectious Diseases, Michael Reese Hospital, Lake Shore Drive at 31st St., Chicago, IL 60616. Copy must be typed, doublespaced, and may not exceed jive pages.

\title{
Debra Nadzam, PhD, RN, To Speak at SHEA Luncheon
}

Debra Nadzam, $\mathrm{PhD}$, RN, is currently a Project Manager for Indicator Development in the Department of Outcomes Research and Development at the Joint Commission on Accreditation of Healthcare Organizations (JCAHO). Her clinical background is primarily in psychiatric nursing, including acute-care practice, outpatient, consultation, and clinical specialist activities. In addition, she has taught in the nursing programs at Kent State University and The Frances Payne Bolton School of Nursing at Case Western Reserve University.

Dr. Nadzam also has had extensive administrative experience, including a position as Quality Assurance Clinician for Psychiatric Nursing at The University Hospitals of Cleveland, Director of Nursing Information Resources and Director of Nursing Research at the Cleveland Clinic Foundation, and Director of Nursing

Research and Quality Assurance at Northwestern Memorial Hospital in Chicago, Illinois. She has published and presented papers in the areas of quality assurance, as well as a variety of administrative, clinical, and statistical topics. Her research has focused on depression in the elderly and provision of healthcare services.

She earned her BSN from The University of Michigan, and her MSN in psychiatric nursing from The Frances Payne Bolton School of Nursing at Case Western Reserve University. Her $\mathrm{PhD}$, also in nursing, is from Case Western Reserve University, where she minored in applied statistics.

Dr. Nadzam will be the featured luncheon speaker at the annual SHEA luncheon, October 1, 1991, from 11:45 A.M. to 1:15 PM., in the McCormick Hotel, Rooms 8-10, Chicago, Illinois. 